\title{
Embedding Review and Drill in Teaching Technical Writing
}

\author{
REMUEL M. COLES \\ Surigao State College of Technology
}

\begin{abstract}
This study aimed to determine the effectiveness of embedding review and drill as a strategy in teaching technical writing to the second year students of Bachelor in Architectural Engineering Technology (BArET) at Surigao State College of Technology, Surigao City. It also probed the respondents' level of writing competency both in the control and experimental groups as to grammatical accuracy, paragraph organization, and mechanics before and after instruction. Moreover, it investigated the significant difference on the writing competency of the respondents in both groups exposed to the conventional and review-and-drill strategy of instructions.
\end{abstract}

The study employed a quasi-experimental research design. A research-made questionnaire was used to gather the data from the eighty $(80)$ respondents. The data were analyzed through Mean and Standard Deviation, T-test for dependent and independent samples.

Results revealed that the writing competency of the respondents in the control and the experimental groups did not meet expectations before instruction. However, after instructions were given, writing competency of the former became "accomplished" while that of the latter became "exemplary".

With regard to the effectiveness of the two instructions, both are effective; but the embedded review-and-drill strategy prevailed more effective based on the mean gains obtained by the respondents in the experimental group.

Based on the foregoing findings of the study, the following conclusions were drawn: the writing competency of the respondents has improved after embedding review and drill as a new strategy of teaching and the conventional one as well. Nevertheless, they both excelled after being taught with lessons using different instructions; the conventional and the embedded review and drill in teaching technical writing are effective in developing writing competency of the students; and, embedding review and drill in teaching technical writing is more effective compared to the conventional instruction.

\section{INTRODUCTION}

Teaching writing is essential to students in all academic disciplines. Apart from writing formally and accurately, students should be able to acquire adequate content and knowledge on specific components and objectives of any writing tasks. However, on the pedagogical aspect, the teacher must design varied writing activities to impart competence to the students - allowing them to commit mistakes, improve, and perfect over time. Hence, acquiring technical writing competency will pave the way for the students to succeed both academically and professionally.

Given this importance, industries report that students graduating from technical programs are generally not wellprepared for the writing requirements of the contemporary workplace. Industries naturally have their own set of terminologies committed to the specific requirements and situations exclusive to their form of business. In other words, communicating effectively within an industry is a direct result of an individual's ability to understand and use the industry's vocabulary and communication practices. Effective written communication skills can therefore assist in the acquisition of sought-after contracts and clients as well as assist in maintaining optimal relationships with vital customers (Bradney, 2014).

As presently observed among college students, particularly in technology curricular programs, the skill to master effective writing on business correspondence and technical reports is one of the continuing problems that deeply require functional remedies being indispensable in preparation for their individual workplaces after college education.

It is then the prime objective of the researcher to conduct this study employing a unique pedagogical strategy to address the students' writing incompetence. Through embedding review and drill in technical writing classes, it shall ascertain its effectiveness to the students' level of writing competency.

\section{Conceptual Framework}

This study is anchored on research investigation of Burt, et al., (2011) which emphasized the importance of technical writing skills to technology graduates who are not well-prepared for the writing requirements of the contemporary workplace. 
It is further stressed that without a requirement to master writing skills, the graduate is initially handicapped in his/her chosen professional world. This handicap continues until these skills are acquired. This is despite dramatic increases in mandatory reading, writing, and speech courses; writing across the curriculum initiatives; and the heavy emphasis placed on writing skills by business and industry. It is unknown as to why this crucial skill has been and is still being so inadequately addressed. This is considered by some to be the greatest failure of the higher educational system.

Consequently, this study ascertained the effectiveness of embedding review and drill in teaching Technical Writing among the second year students of Bachelor in Architectural Engineering Technology (BArET) of Surigao State College of Technology, Surigao City.

Hence, the first box shown in Figure 1 contains the Pre-Test for students' writing competency particularly on grammatical accuracy (language structure or syntax and diction), paragraph organization (coherence and relevance), and mechanics (spelling, capitalization, and punctuation). The results of the pre-test with the experimental group were used as the bases for the intervention employed during the instruction.

The second box with the left and right boxes are the strategies of teaching Technical Writing, namely, teaching Technical Writing with conventional strategy as control group and teaching Technical Writing with embedded review and drill as experimental group.

According to Krashen (2009), the best way to learn a second language is through total immersion. Therefore, students are expected to be actively engaged in designed classroom activities. The embedded review and drill for experimental group depend on students' weaknesses based on the pre-assessment results.

For the control group, however, is the usual mode of teaching Technical Writing such as overview discussions of the subject matter and direct actual writing of business letters, technical reports, etc.

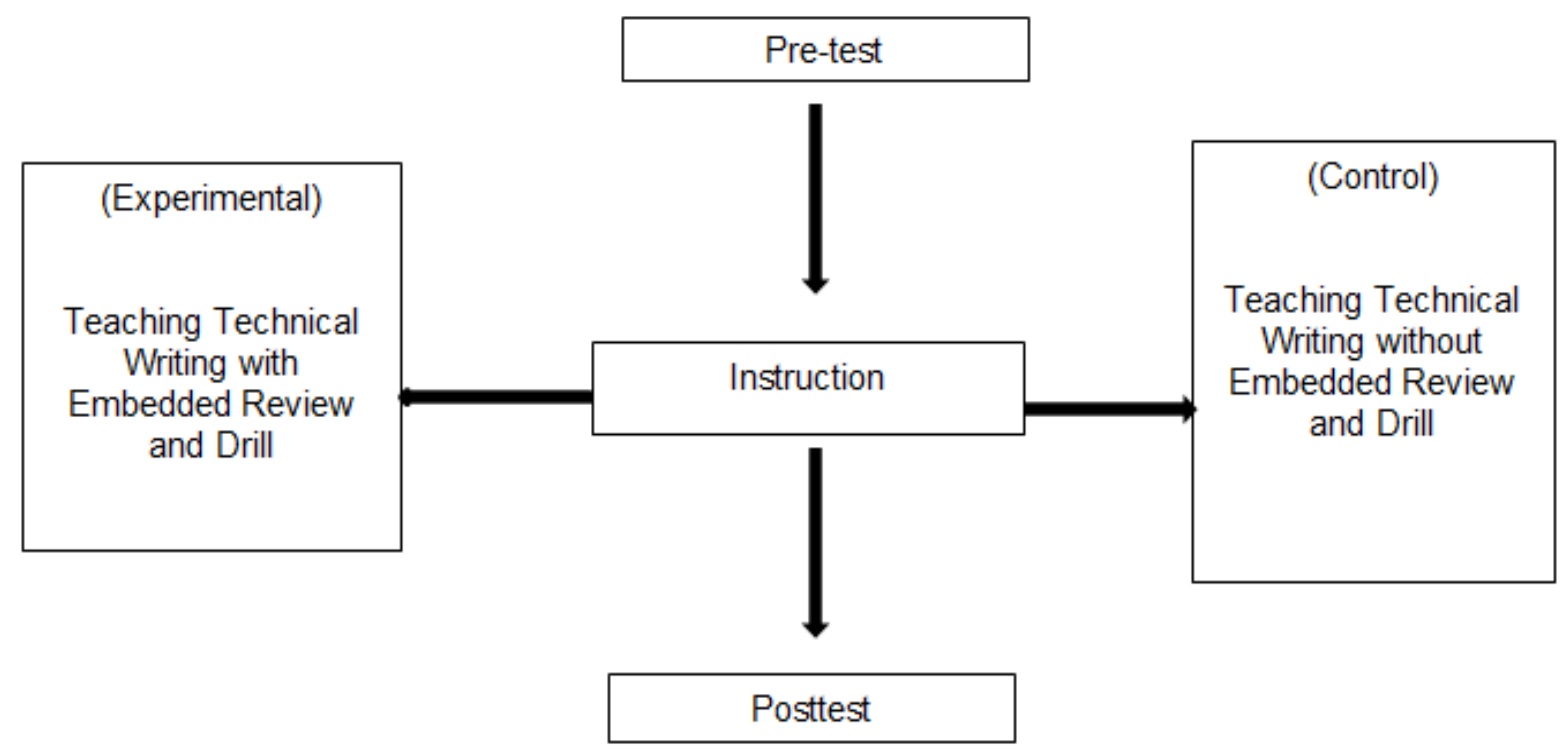

Fig 1

\section{Research Paradigm}

Lastly, the fifth box is the Post-Test for Technical Writing skills in terms of grammatical accuracy, paragraph organization, and mechanics. This part also contains how much the participants have improved in their writing competencies through the mentioned aspects of writing.

\section{Statement of the Problem}

This study aimed to determine the effectiveness of embedding review and drill in teaching technical writing to second year students of Bachelor in Architectural Engineering Technology (BArET) at Surigao State College of Technology, Surigao City.
Specifically, it sought to answer the following subproblems:

- What is the writing competency of the participants before and after instruction in the control and experimental groups as to

$\checkmark$ grammatical accuracy,

$\checkmark$ paragraph organization, and

$\checkmark$ mechanics?

- Is there a significant difference on the writing competency of the participants in the control group and experimental group before and after instruction?

- Is the writing competency of the participants in the experimental group better than the control group after instruction? 


\section{METHOD}

This study employed quasi-experimental design. This research design was utilized to ascertain the effectiveness of embedding review and drill as a strategy in teaching Technical Writing. The design involved two groups of participants, the experimental and the control groups. Both groups were subject for a pre-test and posttest; however, only the experimental group was accorded with experimental treatment.

In this study, the control group was exposed to ordinary and conventional way of teaching. On the other hand, the experimental group was employed with a new strategy. Both groups were in a typical classroom setting with the same lessons. The difference was on the strategy of teaching particularly in experimental group which addressed the weak points of the students' writing competency through the intervention of embedded review and drill.

The study utilized one set of instruments to measure the writing competency of participants as to grammatical accuracy, paragraph organization, and mechanics. The questionnaire (Appendix A) is the pre-test and posttest instrument that covered items on business letter writing (cover letter and resignation letter) and technical report writing (incident/accident report).

Validity. To augment the validity of the instrument, a rubric (Appendix B) was used as a guide. A letter of request (Appendix $C$ ) was sent to two experts to validate the instrument with reference to the content and construct validity.

Reliability. To test the reliability of the instrument, a dry-run test (Appendix E) was employed to the nonparticipants of the study.

\section{Ethics and Data Gathering Procedure}

A letter of request was forwarded to the Chair of the College of Industrial Technology (CIT) for the conduct of the study.

Upon approval, a coin was tossed to identify which section would serve as control group and which section would be the experimental group.

The research participants individually took the pre-test in a specified duration of time.

After taking the pre-test, the participants in both groups underwent a three-week intensive teaching with parallel content under different types of instruction.

After the intervention, the participants took the same test to find out whether there exists a significant effect, and mean gain from the pre-test scores.

\section{Data Analysis}

The data were analyzed and interpreted with the following statistical tools:

Mean and Standard Deviation. This was utilized to ascertain the writing competency of the participants before and after instruction in the control and experimental groups as to grammatical accuracy, paragraph organization, and mechanics.

T-test for paired samples. This was used to determine the significant difference on the writing competency of the participants in the control group and experimental group before and after instruction.

T-test for independent samples. This was employed to compare if the writing competency of the participants in the experimental group is better than the control group after instruction.

\section{RESULTS AND DISCUSSIONS}

This chapter presents, analyzes, and interprets the gathered data from the respondents. The results and discussions of the gathered data follow the sequence of the problems posted in Chapter 1.

\begin{tabular}{|c|c|c|c|c|c|c|c|}
\hline \multirow{2}{*}{ Competency } & \multirow{2}{*}{ Test } & \multicolumn{4}{|c|}{ Control } & \multicolumn{3}{c|}{ Experimental } \\
\cline { 3 - 8 } & & Mean & SD & Description & Mean & SD & Description \\
\hline \multirow{3}{*}{$\begin{array}{c}\text { Grammatical } \\
\text { Accuracy }\end{array}$} & Pre-test & 1.49 & 0.43 & Beginning & 1.99 & 0.46 & Developing \\
\cline { 2 - 8 } & Post-test & 2.59 & 0.38 & Accomplished & 3.61 & 0.27 & Exemplary \\
\cline { 2 - 8 } & Gain & 1.11 & 0.48 & - & 1.62 & 0.40 & - \\
\hline \multirow{3}{*}{$\begin{array}{c}\text { Paragraph } \\
\text { Organization }\end{array}$} & Pre-test & 1.33 & 0.32 & Beginning & 1.75 & 0.40 & Developing \\
\cline { 2 - 8 } & Post-test & 2.62 & 0.50 & Accomplished & 3.71 & 0.29 & Exemplary \\
\cline { 2 - 8 } & Gain & 1.28 & 0.55 & - & 1.96 & 0.37 & - \\
\hline \multirow{3}{*}{ Mechanics } & Pre-test & 1.70 & 0.45 & Developing & 1.92 & 0.49 & Developing \\
\cline { 2 - 8 } & Post-test & 2.85 & 0.46 & Accomplished & 3.58 & 0.36 & Exemplary \\
\cline { 2 - 8 } & Gain & 1.15 & 0.45 & - & 1.66 & 0.43 & - \\
\hline
\end{tabular}

Table 1:- Writing Competency of the Respondents in Control and Experimental Groups Before and After Instruction 
The Table discusses the writing competency of respondents in the control and the experimental groups before and after instruction.

As presented on the Table above, before the instructional delivery, respondents in the control group as to grammatical accuracy and paragraph organization obtained the average mean of 1.49 with the standard deviation of 0.43 and the latter was 1.3 with 0.32 , respectively. The results depict that respondents manifest beginning level of their technical writing competency. As to mechanics, however, the same respondents gained the average mean of 1.70 with the standard deviation of 0.45 which means that the respondents were already in the developing level.

On the other hand, the respondents in the experimental group before instruction was given were labeled developing in all competencies. It can be observed that as to grammatical accuracy, the respondents obtained the average mean of 1.99 with the standard deviation of 0.46. As to paragraph organization and mechanics, however, the respondents incurred an average of 1.75 with the standard deviation of 0.40 and the latter has of 1.92 with 0.49 respectively.

The description beginning means that all sentences have fragment or grammatical errors; all information is inaccurate and incomplete; and capitalization, punctuation, and spelling are erroneous. Developing likewise denotes that most sentences have fragment or errors; some information is complete and correct; and some punctuation, capitalization, and spelling are correct.

In the same manner, after the instructional delivery, the respondents in the control group were labeled accomplished in all areas of competency having gained the average means of $2.59,2.62$, and 2.85 , with the standard deviations of $0.38,0.50$, and 0.46 correspondingly. The results indicated that the respondents manifested improvement on their writing competency regardless of strategies employed in teaching technical writing.

However, the respondents in the experimental group after instruction was given were labeled as exemplary in all areas of competency having gained the average means of $3.61,3.71$, and 3.58 with the standard deviations of 0.27 , 0.29 , and 0.36 respectively.

These results imply that respondents in the experimental group achieved the exemplary level of writing competence specifically on the grammatical accuracy, paragraph organization, and mechanics. It is then evident that the embedded review-and-drill as a strategy of teaching greatly influenced the competency level of the respondents.

The description accomplished explains that most of the language features or items are accurately observed while the description exemplary means that all language facets are excellently put into writing.

As observed, most students exposed to embedded review-and-drill instruction manifested greater level of writing competency because they personally allowed themselves to commit mistakes, rectify them, and perfect overtime. Through this mode of language learning delivery, students were immersed into metalinguistic or reflective function in language for they are the ones to construct, reconstruct and modify sentences or paragraphs to the most appropriate form and content. It is evidently learnercentered; whereas, respondents in the conventional strategy achieved only the accomplished level of competency because they became passive in the process of learning where lecture method was only employed.

Table 2 demonstrates the Pre-Post test difference on the writing competency of the respondents before and after instruction.

\begin{tabular}{|c|c|c|c|c|c|}
\hline Group & Control & T & p & Decision & Interpretation \\
\hline \multirow{3}{*}{ Control } & Grammatical Accuracy & 14.76 & $8.9 \mathrm{E}-18$ & Rejected & Significant \\
\cline { 2 - 5 } & Paragraph Organization & 14.94 & $5.9 \mathrm{E}-18$ & Rejected & Significant \\
\cline { 2 - 5 } & Mechanics & 16.18 & $3.8 \mathrm{E}-19$ & Rejected & Significant \\
\hline \multirow{3}{*}{ Experimental } & Grammatical Accuracy & 25.81 & $4.0 \mathrm{E}-26$ & Rejected & Significant \\
\cline { 2 - 5 } & Paragraph Organization & 33.36 & $2.7 \mathrm{E}-30$ & Rejected & Significant \\
\cline { 2 - 5 } & Mechanics & 24.38 & $3.2 \mathrm{E}-25$ & Rejected & Significant \\
\hline
\end{tabular}

Table 2:- Difference on Writing Competency before and After Instruction

Gleaned from the Table are the notable results on the comparison of Pre-test and Posttest scores of the respondents in each factor.

Uniform results were obtained based on the indicated p-values per factor in each group. In the control group, the t-values obtained are 14.76, 14.94, and 16.18 as to grammatical accuracy, paragraph organization, and mechanics respectively. These t-values resulted into $\mathrm{p}$ values which are all less than 0.05 . These brought the rejection of their corresponding null hypotheses. This means that there is a significant difference between the pretest and posttest results in the control group. Thus, the writing competency of the respondents in the conventional teaching strategy has improved.

Similarly, the t-values obtained by the respondents in the experimental group as to grammatical accuracy, paragraph organization, and mechanics were 25.81, 33.36, and 24.38 respectively; these t-values also obtained p- 
values which are all less than 0.05 which led the rejection of the null hypotheses. This also means that there is a significant difference on the pre-test and posttest performances of the respondents in the experimental group. Hence, the new strategy employed has also improved.
Therefore, these results entail that instructions in both groups were effective.

Table 3 displays the difference between the mean gains of the students in the control and experimental groups as to comparison of effectiveness between the two methods of teaching technical writing.

\begin{tabular}{|c|c|c|c|c|}
\hline Competency & $\mathbf{T}$ & $\mathbf{p}$ & Decision & Interpretation \\
\hline Grammatical Accuracy & 5.22 & $1.4 \mathrm{E}-06$ & Rejected & Significant \\
\hline Paragraph Organization & 6.44 & $8.5 \mathrm{E}-09$ & Rejected & Significant \\
\hline Mechanics & 5.21 & $1.5 \mathrm{E}-06$ & Rejected & Significant \\
\hline
\end{tabular}

Table 3:- Difference on Mean Gains between Control and Experimental Groups

The Table exhibits t-values of 5.22, 6.44, and 5.21 with p-values of $1.4 \mathrm{E}-06,8.5 \mathrm{E}-09$, and $1.5 \mathrm{E}-06$ as to grammatical accuracy, paragraph organization, and mechanics respectively. Since the p-values are less than 0.05 , the null hypotheses were rejected indicating the significant difference between the mean gains of the control and experimental groups. As mentioned above, the control group had mean gains of $1.11,1.28$, and 1.15 while the experimental group had mean gains of 1.62, 1.96, and 1.66 both as to grammatical accuracy, paragraph organization, and mechanics respectively.

These show that the mean gains in the experimental groups are greater than those of the control group. Thus, the results imply that embedding review and drill as a strategy in teaching Technical Writing is more effective in developing all areas of students' writing competency particularly in grammatical accuracy, paragraph organization, and mechanics.

Embedding review and drill activities in the classroom is more effective because it allows students to interact with one another communicatively. As McCaul (2012), in her article entitled "Drills in Language Teaching", stressed that students enjoy drills; thus, the teacher should make the drills contextualized, situational and interesting. She further emphasized that the primary aim in the use of drills is for the student to be able to transfer his drill habits into his conversation. In order to accomplish this, it is necessary for the student to be intellectually and, if possible, emotionally involved in the activity.

In addition, Hedge (2012) mentioned features of effective writing: a high degree of accuracy, complex grammar devices, and a careful choice of vocabulary and sentence structures in order to create style, tone and information appropriate for the readers of one's written text. All these points make the teaching of writing a complex matter, since all of these should be taken into consideration for efficient learning of writing strategies.

Likewise, Marzano (2012) recommended that what a teacher could typically do is to engage students in a brief review of content that highlights the critical information.
The teacher uses specific strategies to review information: summary, problem(s) that must be solved using previous information, question(s) that require a review of content, demonstration, and brief practice test(s) or exercise(s). When necessary, the teacher reteaches basic information or skills. Evidence that students grasp the previous content includes, when asked, being able to describe the previous content on which the new lesson is based, and responding to class activities in a way that indicates that they can recall the previous content.

\section{CONCLUSIONS AND RECOMMENDATIONS}

\section{A. Findings}

The following are the findings of the study:

The writing competency of the respondents in the control and the experimental groups did not meet expectations before instruction. However, after instructions were given, writing competency of the former became accomplished while that of the latter became exemplary.

$>$ There is a significant difference on the writing competency of the participants in both groups before and after instruction.

$>$ The writing competency of the respondents in the experimental group is better than the control group after instruction.

\section{B. Conclusions}

Based on the above-cited findings, the following conclusions were drawn:

$>$ The writing competency of the respondents has improved after embedding review and drill as a new strategy of teaching and the conventional one as well. Nevertheless, they both excelled after being taught with lessons using different instructions.

$>$ The conventional and the embedded review and drill in teaching technical writing are effective in developing writing competency of the students.

Embedding review and drill in teaching technical writing is more effective in developing writing competency compared to the conventional instruction. 


\section{REFERENCES}

[1]. Adas, D. and Bakir, A. (2013). Writing Difficulties and New Solutions: Blended Learning as an Approach to Improve Writing Abilities. International Journal of Humanities and Social Science, Vol. 3, No. 9, May 2013. Retrieved from https://staff.najah.edu/sites/default/files/28.pdf

[2]. Ahmed, S. A. (2010). Exploring Students' Perceptions of ESL Writing. United Arab Emirates University. English Language Teaching, 4, 2, 73-83. Retrieved from www.Ccsenet.Org/journal/index.php/elt/article/downl oad/10770/63?origin=publication_detail

[3]. Alcantara, R. and Espina, F. (2010). Technical Writing for Filipino Students. Makati City: Katha Publishing Co., Inc.

[4]. Al-Khasawneh, F. (2010). Writing for Academic Purposes: Problems faced by Arab postgraduate students of the college of business, UUM. ESL World, Issue 2 (28) vol. 9, 2010. Retrieved from http://www.esp-world.info

[5]. Brown, H .D. (2001). Principles of Language Learning and Teaching.4th edition. White plain New York: Longman.

[6]. Hedge, T. (1999). Writing, Oxford: O.U.P., 11th Edition Lee, Betsy. B. Activities for Developing Motivation and Memory Skills by Learning Abilities Books. Retrieved on July 3, 2009 from the World Wide Web: http://www.learningbooks.net/.

[7]. Khalid, S., Sarwar, J., and Tauseef, R. (2014). Analyzing the Importance of Technical Writing in Professional Industry of Pakistan: International Journal of Social, Behavioral, Educational, Economic, Business and Industrial Engineering, Vol. 8, No. 10, 2014. Retrieved from http://waset.org/pdf/books/?id=14181

[8]. Krashen, Stephen D. (1984) "Writing: Research, Theory, and Applications." Language Teaching Methodology Ser. Oxford: Pergamon Institute of English, 1984.

[9]. Menoy, J. (2013). The Simplified Research and Technical Report Writing. Mandaluyong City: Books Atbp. Publishing Corporation.

[10]. Miranda, F. and Roma-Mirasaol, J (2011). Communication Skills: Writing in the Discipline. Quezon City: Katha Publishing Co., Inc.

[11]. Rosenshine, B. (2012). Principles of Instruction: Research-based Strategies that All Teachers Should Know. Retrieved from:https://www.aft.org/sites/default/files/periodicals /Rosenshine.pdf

[12]. Watkins, P. (2004) Writing, English Teaching Professional, Issue 30, January 2004. 